\title{
Dietary Adequacy of school Going Children in Selected Areas of Himachal Pradesh
}

\author{
Rajju Priya Soni ${ }^{1}$ and Mittu Katoch ${ }^{2}$ \\ Email: rajjupriyasoni@yahoo.com \\ $1 \& 2$ Senior Research Fellow's, Department of Agronomy, Forages and Grassland Management, CSK HPKV, \\ Palampur (H.P.) 176062 India
}

\begin{abstract}
The objective of the study was to analyse the diet of 7-9 year school going children. A total of 200 school going children were selected from four different of two Districts of Himachal Pradesh viz. Kangra and Kullu were selected, with one rural and one urban block of each District nutritional status of children were determined by standard procedures. Information regarding socioeconomic background, dietary habits, frequency of consumption of foods and clinical symptoms were recorded. Data on dietary intake was collected by 24 hour recall method and analysed for food and nutrient intake which was calculated and compared with Recommended Dietary Intake/ Recommended Dietary Allowances. Results indicate that most of the rural and urban blocks school children had nuclear families and belonged to SC castes. Regarding family income $66 \%$ and $52 \%$ of the families of school children had family income Rs. 2000-4000/-. A large percentage of $180 \%$ and 77\%) selected school children were non-vegetarian. Intake of all the food groups such as cereals, pulses, green leafy vegetables, roots and tubers, other vegetables, milk and milk products, sugar and jaggery was lower than $R D I$, but intake of fat was significant $(P \leq 0.05)$ in all selected school children. Intake of protein, energy, calcium, iron, carotene, thiamine, riboflavin and niacin was lower than RDA. Intake of fat and ascorbic acid was more than RDA in all the subjects
\end{abstract}

\section{Introduction}

Malnutrition has been defined as a "pathological state resulting from a relative or absolute deficiency or excess of one or more essential nutrients", it is one of the principle public health problems affecting large sections of populations especially children in developing countries (Begum and Nessa 2008).

Diet is one of the prime determinants of health and nutritional status. An inadequate diet, poor in both quality and quantity has been one of the reasons for high levels of malnutrition in children, Dietary surveys are therefore one of the essential components of nutritional assessment. Assessing dietary adequacy in terms of quality and quantity is equally important. School age is a precious time for acquisition of skills that permits independence in eating and developing liking and disliking of food. Development of good food habits and nutritional practices in early childhood establish the foundation for adult health.

Nutrition plays a vital role as inadequate nutrition during childhood may lead to malnutrition, growth retardation, reduced work capacity and poor mental and social development (Sharma and Chawla 2005).Keeping this in view it becomes very important to know the nutritional status of school going children, the building blocks of state and country and hence the present study was carried out in Selected areas of Himachal Pradesh with the following objectives

1. To assess information regarding dietary consumption and clinical status of selected school going children.

2. To compare the dietary and anthropometry of the school going children with the standards.

\section{Materials And Methods}

Two Districts of Himachal Pradesh namely Kangra and Kullu were selected. One rural and one urban block of each District were selected purposively for the present investigation. Two Government schools from each block were selected randomly. A total number of two hundred children were selected randomly. A Survey was used in order to obtain the information required.

Survey Schedule: The schedule was use to collect the information on socioeconomic profile, dietary habits, dietary intake and clinical status.

Diet Survey: The food Consumption frequency was recorded in terms of cereals, pulses, green leafy vegetables, roots and tubers, other vegetables, milk and milk products, Fats and oils and sugar and jaggery. The daily dietary 24 hour recall method for three consecutive days was taken and was averaged out for one day. The average daily mean intake was calculated with the help of food consumption tables of Gopalan ., The calculated 
daily nutrient intake in terms of protein, fat, energy, calcium, iron, carotene, thiamine, riboflavin, niacin and ascorbic acid were than compared against recommended dietary allowances for Indians.

Clinical Survey: All the selected school going children were examined for the presence or absence of any clinical signs of nutritional deficiencies and presence of infection and other illness. A medical practitioner was associated for clinical assessment of subjects and the clinical symptoms observed were noted in the structured schedule.

\section{Results And Discussion}

Data obtained was analysed with respect to the objectives of the present study

\section{Socio economic Profile and Dietary Habits}

Data presented in table 1

Majority of selected school going children of rural and urban blocks of Both Districts had nuclear families ( 63 and $79 \%$ of rural and urban blocks respectively) as compared to joint families(47 and $21 \%$ of rural and urban blocks respectively) Regarding caste, $50 \%, 8 \%, 17 \%$ and $25 \%$ children of rural blocks belonged to SC, ST, OBC and general respectively, whereas $48 \%, 4 \%, 17 \%$ and $31 \%$ children of urban blocks belonged to SC, ST, OBC and general respectively Similarly Chauhan reported that that majority of the govt. school children $(61 \%)$ belonged to lower caste followed by middle caste $(27 \%)$ and higher caste $(12 \%)$, whereas maximum proportion of Private school children belonged to higher caste $(64 \%)$ followed by lower $(20 \%)$ and middle caste $(16 \%)$.

The results revealed that more than $50 \%$ family monthly income of selected school children of both districts had income ranging from 2000 to $4000 /-$ per family.

\section{Dietary habits}

Details of the food habits depicted that most ( 80 and $77 \%$ of the rural and urban blocks) children were non vegetarian followed by vegetarian ( 20 and $23 \%$ of rural and urban blocks resp.). Majority of children were not taking packed lunch. The decline in the practice of taking packed lunch may be attributed to the ongoing mid-day meal programme in the schools.

\section{Food Consumption}

Daily Mean Intake of selected school children are presented in table 2. Daily mean intake of cereals was $136.03 \pm 3.75 \mathrm{~g}$ and $135.74 \pm 3.70 \mathrm{~g}$, respectively in rural and urban blocks of both Districts. Intake of cereals was almost same in both Districts which was significantly lower than RDI ( $270 \mathrm{~g})$

Daily mean intake of pulses by school children was $42.52 \pm 3.20 \mathrm{~g}$ and $41.52 \pm 2.55 \mathrm{~g}$ of rural and urban blocks of both Kangra and Kullu Districts, respectively and was slightly lower than the RDI (60 g). Lesser intakes were also reported by Chauhan (2001) i.e. only $35.8 \pm 12.58 \mathrm{~g}$ by school children of Palampur region.

Daily mean consumption of green leafy vegetables by school children of rural and urban blocks of Kangra and Kullu District school children was $24.02 \pm 7.11 \mathrm{~g}$ and $30.17 \pm 7.55 \mathrm{~g}$ respectively and was lower than the RDI (100 g). Lesser amount of green leafy vegetables were consumed because children did not like the taste. Mothers were also not aware of the importance of green leafy vegetables in the diet. Similarly lower intake of green leafy vegetables was reported by Neelam 2002.

Daily mean intake of roots and tubers by school children of rural and urban blocks of Kangra and Kullu Districts was more $(89.48 \pm 7.28 \mathrm{~g}$ and $80.15 \pm 6.77 \mathrm{~g}$, respectively) as compared to earlier findings. The value of both blocks school children was lower than RDI $(100 \mathrm{~g})$. Less intake of roots and tubers was reported by Chauhan (2001)

The results of the present study showed higher intakes of other vegetables as compared to earlier studies conducted in other areas of the state. The daily mean consumption of other vegetables by school children of rural and urban blocks of Kangra and Kullu Districts was $89.08 \pm 9.07 \mathrm{~g}$ and $78.85 \pm 8.43 \mathrm{~g}$, respectively. Children of both Districts consumed other vegetables. Cauliflower and peas were consumed weekly. According to Chauhan (2001), less intake of other vegetables was reported i.e. $40.6 \pm 20.7 \mathrm{~g}$ by government school children of Palampur region.

Children of both the blocks preferred to consume cow's milk than buffalo's and goat's milk. The daily mean consumption of milk and milk products by rural and urban blocks school children of Kangra and Kullu Districts was $81.32 \pm 7.28 \mathrm{~g}$ and $92.18 \pm 9.75 \mathrm{~g}$, respectively was less as reported by Neelam (2002) the daily consumption of milk and milk products by Chowari and Bharmour school children was $117.50 \pm 5.74 \mathrm{~g}$ and $126.80 \pm 5.35 \mathrm{~g}$, respectively. Intake of milk and milk products by school children of both the blocks was significantly less than RDI $(250 \mathrm{~g})$.

The Daily mean intake of fat and oil was almost same in $(19.63 \pm 0.84 \mathrm{~g}$ and $18.23 \pm 0.40 \mathrm{~g})$ by rural and urban blocks school children of both Districts, respectively and which was lower than the RDI $(25 \mathrm{~g})$. The daily 
mean intake of sugar and jaggery was almost same $(27.57 \pm 1.49 \mathrm{~g}$ and $27.43 \pm 1.72 \mathrm{~g}$, respectively) in rural and urban blocks of both Districts which was slightly lower than the RDI (50g) but higher than reported earlier. According to Neelam (2002), daily mean intake of sugar and jaggery by Chowari and Bharmour school children was $7.65 \pm 0.34 \mathrm{~g}$ and $8.40 \pm 0.27 \mathrm{~g}$, respectively which was much lower than RDI $(50 \mathrm{~g})$.

\section{Nutrient intake}

Daily mean intake of protein by school children was $23.31 \pm 0.78 \mathrm{~g}$ and $29.33 \pm 0.84 \mathrm{~g}$, respectively of rural and urban blocks of Kangra and Kullu Districts which was much less than the recommended level $(41 \mathrm{~g})$ and the difference was non significant at $5 \%$ level of significance. Khasi girls of Meghalaya were also reported to have lower protein (33.48 gm in 7-12 years) intake than RDA (Agrahar 2005).

Daily mean intake of fat by school children of rural and urban blocks of Kangra and Kullu Districts was $27.00 \pm 1.00 \mathrm{~g}$ and $26.72 \pm 1.25 \mathrm{~g}$. The intake of fat and oils was slightly higher than RDA ( $25 \mathrm{~g})$. Difference between the mean and standard values was non-significant at $5 \%$ level of significance. As reported by Hira et al. (1999) intake of fat by rural school girls was $31.5 \mathrm{~g}$ which was higher than the recommended level.

Daily mean energy intake by school children of rural blocks of Kangra and Kullu Districts was $1050.82 \pm 20.94 \mathrm{Kcal}$ whereas intake of energy by school children of urban blocks of both the Districts was $1038.26 \pm 21.75 \mathrm{Kcal}$ which was lower than RDA $(1950 \mathrm{Kcal})$. Difference was non-significant at $5 \%$ level of significance. Less intake of energy may be attributed to less food intake. Similarly Khasi girls of Meghalaya were also shown lower energy (1268.32 kcal in 7-12 years) intake than RDA. (Agrahar 2005).

The average intake of calcium by school children of rural blocks of Kangra and Kullu Districts was $299.93 \pm 20.43 \mathrm{mg}$. The intake of calcium by urban blocks of both Districts school children was303.92 $\pm 18.64 \mathrm{mg}$ which was lower than RDA (400g) and the difference was non-significant at $5 \%$ level of significance. Lower intakes may be due to lesser intakes of milk, cereals and other foods. Same findings of lower intake of calcium $(335.46 \pm 98.78 \mathrm{mg})$ was reported by Chauhan (2001).

Daily mean intake of iron by school children of rural and urban blocks of Kangra and Kullu Districts was $8.32 \pm 0.5 \mathrm{mg}$ and $8.37 \pm 0.59 \mathrm{mg}$, respectively which was lower than RDA $(26 \mathrm{mg}$ ) and the difference was non-significant at $5 \%$ level of significance.. Lower intakes could be due to less food intake especially green leafy vegetables. Chauhan (2001) reported that intake of Iron was slightly lower than RDA (26 mg).

The daily mean intake of carotene by school children of rural blocks of Kangra and Kullu Districts was $1237.57 \pm 283.15 \mu \mathrm{g}$. The intake of carotene by urban blocks of both Districts school children was $1626.55 \pm 329.57 \mu \mathrm{g}$ which was lower than RDA $(2400 \mu \mathrm{g})$ and the difference was non-significant at $5 \%$ level of significance. Since the weekly consumption of carrots ranged from $78-83 \%$ of selected school subjects that too when in season resulted in lower carotene intake. Chandana and Sehgal (1995) reported that intake of $\beta$ carotene was slightly lower than RDA in school children in Panipat city of Haryana.

Daily mean intake of thiamine by school children of rural and urban blocks of Kangra and Kullu Districts was $0.74 \pm 0.03 \mathrm{mg}$ and $0.75 \pm 0.02 \mathrm{mg}$ respectively which was slightly lower than RDA $(1.0 \mathrm{mg})$. and the difference was non-significant at $5 \%$ level of significance. Inadequate intake of thiamine was reported by Chauhan (2001). Less intake of thiamine may also have been resulted from lower cereal intake as compared to RDA.

Daily mean intake of riboflavin by school children of rural and urban blocks of Kangra and Kullu Districts was $0.52 \pm 0.02 \mathrm{mg}$ and $0.54 \pm 0.03 \mathrm{mg}$ which was lower than RDA $(1.2 \mathrm{mg})$. ). Difference was non significant at $5 \%$ level of significance. As found from the earlier studies the intakes were higher than that of the present study but the values were less than the recommendations. Lower intake could be due to less food intake. less intake of riboflavin was reported by Chauhan (2001) i.e. $0.96 \pm 0.28 \mathrm{mg}$ in government school children.

Daily mean intake of niacin by school children of rural blocks of Kangra and Kullu Districts was $4.25 \pm 0.23 \mathrm{mg}$. The intake of niacin by urban blocks of both Districts school children was $6.37 \pm 0.20 \mathrm{mg}$. Intake of niacin was lower than RDA (13 mg) and the difference was non-significant at $5 \%$ level of significance.

Daily mean intake of ascorbic acid by school children of rural and urban blocks of Kangra and Kullu Districts was $55.80 \pm 6.50 \mathrm{mg}$ and $55.23 \pm 6.04 \mathrm{mg}$ respectively which was higher than RDA (40 mg) but the results were statistically non-significant at $5 \%$ level of significance. Higher values could be due to sufficient intake of cauliflower, cabbage, mustard leaves and tomato etc. Neelam (2002) reported that intake of ascorbic acid by Chowari and Bharmour school children was $94.43 \pm 10.74 \mathrm{mg}$ and $81.54 \pm 10.99 \mathrm{mg}$ which was higher than RDA (40 mg)

Clinical Survey: Information regarding clinical assessment of school going children of both the blocks has been discussed in table 4

Thirteen and $32 \%$ children in rural blocks and $31 \%$ in urban blocks had good appearance. $59 \%$ children in rural blocks and $65 \%$ in urban blocks had normal appearance whereas $9 \%$ children in rural blocks 
and $4 \%$ in urban blocks had poor appearance. Gill et al. (2008) conducted a study on nutritional status of 812 rural Primary school children from 6 to 15 years and found that, only $2 \%$ had a good physique whereas $39.9 \%$ had fair and $58.1 \%$ had poor physique.

Majority of rural (67\%) and urban (58 \%) school children had normal hair conditions. $19 \%$ school children in rural blocks and $17 \%$ in urban blocks was observed loss of lustre. $3 \%$ school children in rural blocks and $9 \%$ in urban blocks was observed discoloured hair. In rural (11\%) and urban blocks (6\%) easy pluckability was observed in children of Kangra and Kullu Districts respectively. Prabhakar and Gangadhar (2009) reported that majority of the children had lack of lustre (94.1\%), sparseness (94.1\%) and straightness $(83 \%)$ in hair.

The findings of present study showed that Majority of school children of rural blocks (98\%) and urban blocks (95\%) \% had normal eyes in both the Districts. Pale conjunctiva was observed in $2 \%$ school children of rural blocks and $5 \%$ in urban blocks due to iron deficiency. Handa et al. (2008) conducted in a study on assessment of nutritional status of 7-10 years school going children of Allahabad District and reported that, Conjunctiva paleness was noticed only in a small proportion (5.08 \%) of the subjects. Low food and nutrient intake was the main reason responsible for presence of these deficiency disease.

Majority of school children rural blocks (78\%) and urban blocks (82\%) had normal lips. Angular stomatitis was not observed in any children of rural and urban blocks of both districts. Only $10 \%$ children in rural blocks and $3 \%$ in urban blocks was observed angular scar in both the Districts. Cheilosis was observed in $12 \%$ school children of rural blocks and $15 \%$ of urban blocks of both the District. Low food and nutrient intake was the main reason responsible for presence of these deficiency disease. Angular stomatitis (2.66\%) and chelosis (5.33\%) were found in school children (aged 6-12 years) of rural Bihar reported by Kumari and Jain (2005).

Most of the children of rural (64\%) and urban blocks (66\%) of Kangra and Kullu Districts had normal tongue. $28 \%$ school children in rural blocks and $24 \%$ in urban blocks had pale but coated tongue. Red and raw tongue was observed in $8 \%$ school children in both rural blocks and urban blocks. Fissured was not observed in any subject. Only $2 \%$ children had smooth tongue in urban blocks of Kangra District. Chauhan (2001) reported that $16 \%$ of the Government school children had pale but coated tongue, $6 \%$ of the Government school children had red and raw tongue, respectively. $4 \%$ of the Government school children showed fissured tongue.

In both the Districts, $57 \%$ of school children in rural blocks whereas $41 \%$ in urban blocks had no fluorosis. Most of the children (40\%) of rural blocks of both the Districts had chalky teeth whereas only $28 \%$ of school children in urban blocks had chalky teeth. Only $3 \%$ of school children in rural blocks, whereas $12 \%$ of school children in urban blocks had mottled and pigmented teeth in Kangra and Kullu Districts. Prabhakar and Gangadhar (2009) conducted a study on Nutritional Status of Jenukuruba Tribal Children in Mysore District, Karnataka. It was reported that dental fluorosis and dental caries was seen in $46.7 \%$ and $30.4 \%$ selected children.

In both the Districts, $34 \%$ of school children in rural blocks whereas $28 \%$ in urban blocks had no caries. There was slight caries in $21 \%$ of rural blocks school children whereas $23 \%$ of urban blocks school children. Marked caries was observed to be $45 \%$ in rural blocks whereas $49 \%$ in urban blocks school children of Kangra and Kullu Districts. Slight caries was observed in 24 and $63 \%$ of Chowari and Bharmour block school children, 32 and $12 \%$ of marked dental caries was observed in both blocks school children (Neelam 2002).

Regarding gums, in rural blocks, more than half \% (53\%) children had normal gums whereas in urban blocks majority of $(68 \%)$ the children had normal gums. $37 \%$ in rural blocks whereas $32 \%$ in urban blocks school children had bleeding gums. Spongy gums were not observed in any subject. Mittal (1999) conducted a clinical examination of 7-9 years girls belonging to LIG in Ludhiana city and reported that vitamin c deficiency (spongy bleeding gums) was observed in $66.6 \%$ of the subjects.

Thyroid gland was found to be normal in all the subjects in rural and urban blocks of both the Districts i.e., symptoms of thyroid enlargement was not observed. Neelam (2002) reported that the symptoms of thyroid enlargement was not observed in any of the two blocks school children

During skin examination, majority of children of rural blocks (53\%) and urban blocks (64\%) had normal skin appearance. In rural blocks, $22 \%$ and in urban blocks $20 \%$ children had lack of lustre in skin. Dry and rough skin appearance in the school children of Kangra and Kullu Districts was observed to be $25 \%$ in rural blocks whereas $16 \%$ in urban blocks. The poor skin condition of selected school children have been due to their exposure to varied weather conditions and unprotected shelter or irrespective place of residence.

No symptoms of diminished and wrinkled skin was observed in school children of rural and urban blocks of both Districts. Most of the school children in rural blocks (94\%) and in urban blocks (98\%) had normal skin elasticity. In rural blocks, $3 \%$ and in urban blocks only $1 \%$ children had diminished skin, whereas none of the children had wrinkled skin. There were no symptoms of protein energy malnutrition in $82 \%$ of school children in rural blocks and $80 \%$ of school children in urban blocks of Kangra and Kullu Districts 
respectively. Symptoms of oedema was observed in $1 \%$ children of urban blocks in Kangra District whereas muscle wasting was observed in $5 \%$ children of rural blocks of both Districts. $9 \%$ of school children in rural blocks and $6 \%$ in urban blocks had thin sparse hair. In rural blocks, dyspigmentation of hair was observed in 2 $\%$ school children of Kangra District whereas in urban blocks it was observed in $9 \%$ children of Kullu District. The symptom of moon face was not observed in school children of both the Districts. Diffused depigmentation of skin was observed $4 \%$ of children in urban blocks of kangra and Kullu Districts. Neelam (2002) reported that odema, muscle wasting and moon face was not observed in any of the subjects. $3 \%$ of school children of Chowari and Bharmour had dyspigmentation of hair and $2 \%$ of school children of Chowari block had diffused depigmentation of skin. None of these symptoms were observed in Bharmour school children.

After analysing the clinical assessment of selected school children of rural and urban blocks of Kangra and Kullu District, it may be inferred that due to non-inclusion and inadequate food intake of protective and nutritious food as was evident from the meal and dietary pattern and the resulting inadequate nutrient intake and some of the prominent deficiency symptoms were also observed.

\section{Summary And Conclusion}

The above observations may be attributed to poor economic status, Lack of nutritional knowledge may be one of the factors responsible for lower intake of different food groups resulting in inadequate nutrient intake which in turn affect the nutritional status of school going children. Therefore inclusion of all food groups in daily diet of school children is recommended for improving their nutritional status. Emphasis should be laid on growing of green leafy vegetables at the backyard of the houses so that they can consume vegetables and get valueable nutrients like vitamins and minerals in sufficient amount for the improvement of nutritional status. The study emphasized that Nutrition education should be included in primary school curriculum as learning to know "what to eat and why" is an essential aspect of child's education.

The need for more calories, protein and micronutrients like iron and vitamins for the children in the slums can not be overemphasized. Giving iron tablets or micronutrient fortification are not answers to the problem in this situation but what they need is more food which is of good nutritive value. School lunch can be an ideal vehicle to achieve this end. The lunch as it is can be designed to prevent severe malnutrition, and this has been achieved in many countries (India, Kenya, Bangladesh, Sri Lanka, etc). In India already giving lunch to pupils, this is expected to alleviate undernutrition.

Further, there is a need to impart need based nutrition education to mothers to improve the nutritional status of family especially children. Efforts should be made to provide nutrition education to mothers or the persons taking care of the diets of children. The aspects covered may include importance of balanced diet and packed lunch, right choice of foods, nutrient conservation by proper cooking methods, utilization of foods available in season either grown in kitchen gardens or locally available, proper distribution of foods to all the members of family. A proactive role from the government and community leaders is the need of the hour

\section{References}

[1]. Agrahar MD. 2005. Nutritional status of Khasi school girls in Maghalaya. Nutrition 21: 435-431.

[2]. Amuta, Une E and Houmsou RS. 2009. Assessment of nutritional status of school children in Makurdi, Benue state. Pakistan Journal of Nutrition $8: 691-694$.

[3]. Begum M and Nessa Z. 2008. Nutritional status of school going children of a selected school of Dhaka City. Bangladesh. J. Sci. Ind. Res. 43: 97-102.

[4]. Candana S and Sehgal S. 1994. Nutrtional status of school children (7-9 years) a comparative study of boys and girls. The Indian Journal of Nutrition and Dietetics 31: 323-328.

[5]. Chandna S and Sehgal S. 1995. Comparative nutritional status of school going boys and girls (9-12 years) of Panipat city. Journal of Dairying, Foods and Home Science 14: $221-28$.

[6]. Chandna S and Sehgal S. 1997. Effect of family income on the nutritional status of children (6-12 years) Haryana Agricultural University. Journal of Research 27: 45-52.

[7]. Chauhan V. 2001. Assessment of nutritional status of selected school children of Palampur region, M.Sc. Thesis, CSK Himachal Pradesh Krishi Vishvaviayalaya, Palampur.

[8]. Chawla. 1992. Effect of nutritional status on physical work capacity of school going girls. M.Sc. Thesis, Punjab Agricultural University, Ludhiana, India.

[9]. Devi PU and Parvatham R. 2006.Prevelence of iodine and iron deficiencies among selected children and the effect of supplementation of double fortified salt. The Indian Journal of Nutrition and Dietetics 43: 420-428.

[10]. Durrani NR, Ahmad Z and Abbas KA. 2007. Nutritioal and health status of school age children in Islamabad capital Territory. The Pakistan Journal of Pediatrics 31:190-194.

[11]. Gill PS, Prasad BG and Shrivastava RN. (2008) Nutritional status of primary school children in a rural area of Lucknow. The Indian Journal of Pediatrics 35:314-326

[12]. Gopalan C, Rama, Sastri BV, Balasubramaniam SC. 1989. Nutritive value of Indian Foods. Revised and updated by Narasinga, Rao BS, Deosthala YG and Pant KC. National Institute of Nutrition, Indian Council of Medical Research, Hyderabad.

[13]. Goyal J and Kawatra A.1996. Presence of nutrient deficiency signs among rural school going children. Souvenir and Abstracts of scientific presentations in XXIX Annual National Conference of Indian Dietetic Association. PP 100. Held on 27-29 November, 1996 at Punjab Agricultural University, Ludhiana.

[14]. Handa R, Ahamad F, Kumar KK and Prasad R. 2008. Assessment of nutritional status of 7-10 years school going children of Allahabad District. Middle-East Journal of Scientific Research 3: 109-115. 
[15]. Hira CK, Sadana B, Grewal H and Kaur M. 1999. Report All India Coordinated Research Project in Home Science - Food and Nutrition Unit, College of Home Science, Punjab Agricultural University, Ludhiana, India.

[16]. ICMR. 1998. Nutritive value of Indian Foods National institute of Nutrition, Hyderabad.

[17]. Istomin AI, Mikhallov IG and Kozlova AL. 1996. Organization, structure and rationalization of the nutrition of school children of Syktyvkar. Gigiena-i-Sanitariya 8: $15-16$.

[18]. Kataria SR. 1992. Intake of lodine in selected school children in Himachal Pradesh. Ph.D. Thesis Punjab Agricultural University, Ludhiana.

[19]. Kumari P and Kumari D. 2008. Socio-economic, nutritional and health factors influencing the cognitive development of 7-9 year old children. The Indian Journal of Nutrition and Dietetics 45: 1-10.

[20]. Kumari PS and Devadas R. 1990. Growth performance and secular trends among school children of Coimbatore. The Indian Journal of Nutrition and Dietetics. 15: 355.

[21]. Kumari S and Jain R. 2005.Assessment of nutritional status of school children of rural Bihar. The Indian Journal of Nutrition and Dietetics 42: 326-334.

[22]. Mitra M, Kumar PV, Chakraborty S and Bharati P. 2007. Nutriyional status of kamar trial children in Chhattisgarh. Indian Journal of Pediatrics $74: 381-384$.

[23]. Mittal R. 1999 A comparative study of nutritional status and mental ability of girls (7-9 years) of destitute homes and home environment. M.Sc. Thesis, Punjab Agricultural University, Ludhiana, India.

[24]. Neelam 2002. Assessment of Nuritional status of school going children. M.Sc Thesis CSKHPKV,Palampur, India.

[25]. Pant I and Solanki K. 1989. Assessment of health and nutritional status of under privileged school age boys (8-12 year) with special emphasis on vitamin A deficiency. Nutrition Society of India, pp.82.

[26]. Parsad BG. 2007. Assessment of nutritional status of school children in Lucknow. Indian Journal of Pediatrics 16: 181-207.

[27]. Prabhakar JSC and Gangadhar MR. 2009. Nutritional Status of Jenukuruba Tribal Children in Mysore District, Karnataka, Anthropologist 11: 83-88

[28]. Sharma S and Chawla P K. 2005. Impact of Nutrition counselling on anthropometric and biochemical parameters of school girls (79 Years). Anthropologist 7: 121-125.

[29]. Subhadara. 2000. Assessment of the nutritional status of Government and Private school children of Hisar City. M.Sc. Thesis, CCS Haryana Agricultural University, Hisar, India

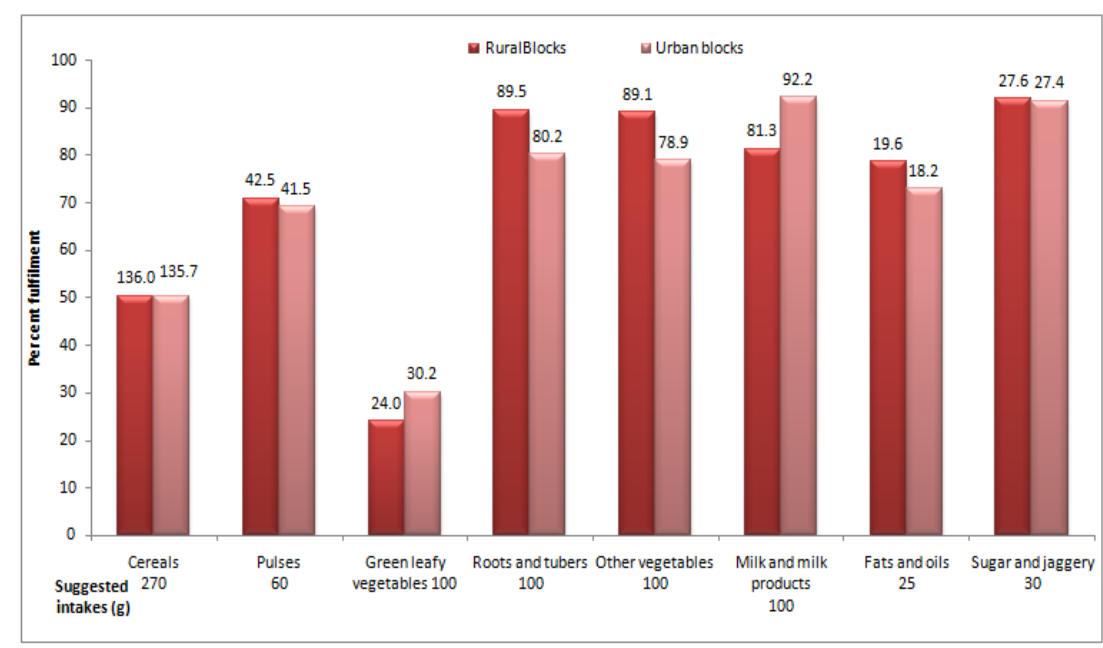

Fig 1 Mean intake by selected school children (7-9 years) of Kangra and Kullu Districts compared with suggested intake for balanced diet (ICMR, 1998)

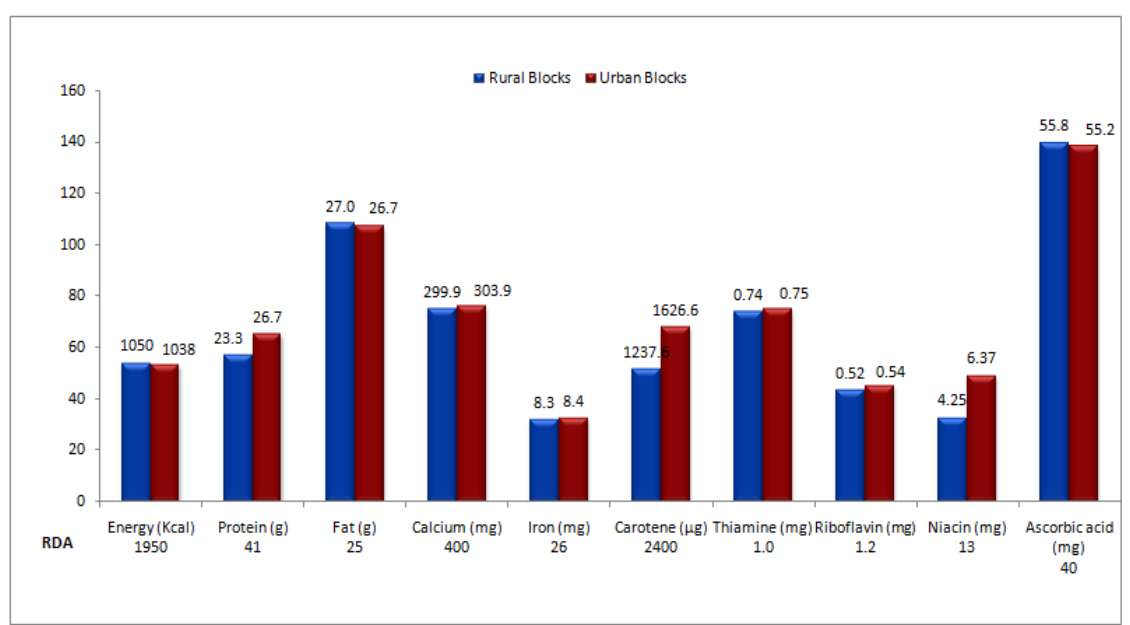

Fig. 2 Nutrient intake by selected school children (7-9 years) compared with ICMR recommendations (1998). 